\title{
Características del desempeño deportivo en dos altitudes y las afectaciones fisiológicas adversas previas a la competición en altura, en futbolistas de alto rendimiento del Club de Fútbol Andrés del Castillo (ADC). Julio 2011
}

Patricia Vega, Santiago Yata, Ito Flores, Luis Sánchez, Jovita Silva, Sonia Antezana, Humberto Gonzales, Manuel Palomino, Segundo Cabrera

Asociación Andrés del Castillo (ADC), distrito San Juan de Lurigancho

Objetivos: Describir las características del desempeño deportivo en dos altitudes y las afectaciones fisiológicas (AF) previas a la competición en altura, en futbolistas de rendimiento alto.

Diseño: Descriptivo, de corte transversal.

Institución: Asociación Andrés del Castillo (ADC), distrito San Juan de Lurigancho.

Participantes: Once futbolistas varones de 16 a 18 años.

Métodos: Se planificó dos partidos de futbol a futbolistas categoría 95. Se jugó los partidos uno en Lima y otro en Huancayo. El estudio se dividió en: a) desempeño deportivo, referente a errores cometidos, como pases errados, desviados; el entrenador cuantificaba errores; b) afectaciones fisiológicas adversas; se aplicó guia de observación, encuesta para valorar las AF previas a la competición.

Principales medidas de resultados: Número de pases errados, remates desviados en llano y en altura y AF previas a la competición.

Resultados: El número de pases errados y remates desviados fueron mayores en la altura que en el llano. Las AF más comunes que presentaron en Huancayo fueron: problemas al respirar (100\%), molestias en el corazón (95\%), náuseas $(80 \%)$, cefaleas $(60 \%)$, insomnio $(90 \%)$, angustia $(80 \%)$, debilidad general $(60 \%)$.

Conclusiones: En el partido de fútbol en altura, aumentaron los pases errados, remates desviados, afectaciones fisiológicas.

Palabras clave: Altura, afectación fisiológica, futbolista de alto rendimiento. 